\title{
Promotion Strategies Are Useful in Adult Learners Examining Social Inequality and Racial Discrimination in Black Americans
}

\author{
Saliza Ramli \\ Professor of Public Administration, National University, Los Angeles, CA USA \\ c/o 269 S. Beverly Dr. \#134, Beverly Hills, CA 90212
}

\begin{abstract}
As we enter the post covid19 pandemic and all the social uprisings and awareness of 2020 and 2022, perhaps there has never been a time in American history where students and educators at all levels need to consider and adapt more effective and innovative approaches to addressing the 'elephant in the American - room' and that being the issue of racism. This paper presents meaningful teaching strategies for adult learners in examining the dark impacts of racism towards African Americans in the United States.
\end{abstract}

\section{Introduction}

America sees itself as a model of social justice, fairness, and equality for all. The USA believes itself to be a beacon of light for the world to emulate, a place of justice for all, and the home of the 'free and the brave.' Today many would argue that this concept is only a myth, and that fairness is not extended to all its citizens equally and that fairness has never included African Americans. The unpleasant truth may be that America as a never embraced people of Color, especially African Americans, and now is the time. For the purposes of this presentation, racial disparities is being defined as meaning an injustice which occurs when there is a significant difference between the percentage of a racial group represented in the general population or the privileged, unfortunately, the United States is plagued with a multiplicity of racial injustices.

This paper entitled, Innovative Teaching Strategies for Adult Learners in Examining the Dark Impacts of Racism towards African Americans in the United States, is designed to equip today's educator with greater insights on issues of racial injustices and inequalities. The assumptions in this paper are: (1) The roots of racism in America are systemic, (2) The are evident in the lack of fairness in our legal and criminal justice systems, and (3) That it is essential to continued progress towards achieving the American dream and informing future discussions on critical community issues and concerns.

"Anti racist pedagogy is a "paradigm located within critical theory utilized to explain and counteract the persistence and impact of racism using praxis as its focus to promote social justice for the creation of a democratic society in every respect" (Blakeney, 2011, p. 119). Innovative strategic approaches in this paper can be useful in the following three areas: (1) to frame community discussions on the origins of institutional racism in America; (2) to provide greater understanding of systemic criminal justice problems in prison terms for African Americans; and (3) to enhance adult learners' opportunities in the provision of quality community service using an informed and evidence-based platform for discussion. There are many criminal justicerelated problems that plague the African American community, however no single impact is as adverse as prison terms, thus it will be used in this presentation as a vibrant example of unfair and unjust culture of evidence. The operational definition in this presentation for prison terms is as follows: Prison terms are sentencing policies govern the administration of legal sanctions for individuals convicted of a criminal offense

The chief strategy to addressing state of racism and black culture is to recognize that it has not improved drastically over the years for African Americans in the United States since their arrival in 1619. The second strategy is to understand that many adult learners are unaware of the connectivity of this history and current dilemmas. The unjust and unfair nature of criminal justice in the United States are deeply aligned with the harsh realities of the history of race relations and the state of the African American. The third strategy is to respond to the urgent need for today's adult learners to enhance overall understanding and comprehension of criminal justice and race in efforts to ensure a more informed society from a holistic approach to systemic racism. Now is the time really begin the serious dialog on civic injustice in the United States of America.

This presentation is significant because it underscores the real need to explore the underpinnings lack of fairness in the criminal justice system in the United States of America in 2021. The author concurs that there is no question that there have been many remarkable and historic developments for African Americans since their arrival to the shores of the New World in 1619 and even more specifically, over the last seventy years; the passage of Brown vs. Board of Education (1954) to the election of President Osama Barak Obama in 2009 on to the election of Vice President Kamala Harris in 2020, to name a few. However, in 2021, the color line is still a real problem in the United States. "Recent high-profile police killings of unarmed Black men and women in the United States garnered national attention. These incidents 
raise questions about the role of race" in the criminal justice system (Headley and Wright 2020). Many African American students feel an obligation to explore the origins of race relations and racism in America to better understand the perceived disconnect between the 'American National Anthem' they sing about and realities they see played out daily by criminal justice systems in their communities. The assumption in this presentation is that most adult learners have some general understanding of inherit rights granted to all citizens of the United States of America under the U.S. Constitution.

\section{Origins of Institutional Racism}

It is essential to start the dialog on American racism with its distasteful origins and to understand how, we as a nation arrived at this point. The chief strategy to addressing state of racism and black culture is to recognize that it has not improved drastically over the years for African Americans in the United States since their arrival in 1619. The second strategy is to understand that many adult learners are unaware of the connectivity of this history and current dilemmas.

Africans along the West Coast of Africa became the target of the White man as early as the 1500s where Europeans had established trading relationships for gold, ivory and some slaves to sell in Europe. After a few generations of this practice, the Spaniards began buying and transporting Africans into the Caribbean Islands mainly to clear the land and dig for precious gold and silver. "In the summer of 1619. A 160-ton ship from the port of Flushing in Holland sailed into Chesapeake Bay...They were seeking to obtain provisions after a season of raiding the West Indies. In exchange for supplies Captain Jope and his crew sold more than twenty Negroes to the local authorities in the struggling English colony of Virginia" (Wood, 2). It has been a 'strange' land for African Americans since their unfortunate arrival in this country.

Black people were first brought to this country as slaves in 1619 , as the primary economic revenue system for building and sustaining the New World. It has been a struggle for Black people from Slavery to Emancipation to Renaissance to Racism to Rebirth, to Mass Incarceration. "Slavery in the United States was the legal institution of human chattel enslavement, primarily of Africans and African Americans, that existed in the United States of America from its founding in 1776 until passage of the Thirteenth Amendment in 1865" (wiki/Slavery). While the institution of slavery was not new, it was harshest in North America. Slavery was not uncommon, it has been practiced for down through the ages, from biblical days through to the European colonization in the Americas. This practice of treating enslaved people as property was carryover from the old world to the Thirteen Colonies which created the United States of America later. Just as the practice of the Britain's colonies, enslaved people could be bought, sold, given or away, and mistreated under the law. Theoretically, slavery lasted in about half of U.S. states until 1865 however; in reality, it was largely replaced by sharecropping and convict leasing, so forth and so on.
The system of 'convict leasing' as a way of forced penal labor in the United States. Historically convict leasing began in the United States as early as 1844 in Louisiana, but it greatly expanded through- out the country after the end of the American Civil War and the emancipation of slaves in 1865. The death of slavery brought the birth of Jim Crow to Blacks. Life immediate after the abolishment of slavery bought a degree of freedom for some Blacks, with the passage of the Thirteenth, Fourteenth, and Fifteen Amendments to the U.S. Constitution and Civil Rights of 1866 and 1870. The Fifteen Amendment gave African American males the right to vote; and elect their first state man. This period of Reconstruction was short lived; for Whites lost their free labor which was fueled by the institution of slavery. Southern whites resisted the new advancements enjoyed by Blacks during this period of life after the Civil War; and sought to reinstate White supremacy and domination of Blacks. All of which gave rise to the myth of black criminality, increased convict leasing and imprisonment of African Americans. 'The backlash against the gains of African Americans in the Reconstruction Era was swift and severe' (Alexander 2020, 30).

According to research, 'corruption, lack of accountability, and racial violence resulted in "one of the harshest and most exploitative labor systems known in American history. African Americans, mostly adult males, due to "vigorous and selective enforcement of laws and discriminatory prison terms," made up the vast majority - though not all-of the convicts leased'. The criminalization of African Americans, especially males has been long standing American practices which is supported by crime statistics falsely showing that Blacks were committing more violent crimes and therefore needed harsher criminal prison terms. Increased contact with the justice system via vagrancy laws, peonage laws, pig laws, etc. that fueled the convict lease system where Blacks were disproportionately leased to private companies as a form of punishment (Wood2020).

In researching the black experience in America from 1877 to 1951 , some historians would say that this period marks the beginning of "the nadir" which is considered to be the darkest hour in American race relations between white and black Americans; however, many African American today would agree that conditions are still extremely harsh and unfair in our 'colorblind' society. There have been many remarkable and historic developments for African Americans from 1954 to 2021; the passage of Brown vs. Board of Education (1954) to the election of President Osama Barak Obama in 2009 on to the election of Vice President Kamala Harris in 2020. However, W.E.B.Du Bois said it best, 'either America will destroy ignorance or ignorance will destroy the United States. (1903)' The unjust and unfair nature of prison terms policies in the United States are deeply aligned with the harsh realities of the history of race relations and the state of the African American.

To summarize the origin of racism and its impact, simply put, in the United States, White people are considered more important (Glaude2016). "America's great promise of equality has always rung hollow in the ears of African Americans. But today the situation has grown even more 
dire. From the murders of black youth by the police, to the dismantling of the Voting Rights Act, to the disaster visited upon poor and middle-class black families by Great Depression" (Glaude2016,1).

\section{Major Systemic Criminal Justice Problem}

The United States of America has the largest criminal justice system in the world. As of 2015, the U.S. had over 6.7 million under some type of correctional control. America has outpaced every nation on earth in its rate of prison terms and incarceration (The Sentencing Project 2018). It is critical to view perceptions of fairness held by college aged African American males on racial injustices and social inequalities because of the urgent need to reach the core of systemic problems in the African American community. Unfair prison terms of Black men impact the economic, social and moral fiber of the African American community. Institutional racism is systematically embedded within the prison terms policies in the criminal justice system of the United States of America.

There is a direct correlation between racism and unfair/unjust prison terms as the major systemic criminal justice problem impact the African American community. So how did the prison grow so quickly to becoming the largest in the world, one may ask. One must visit the birth of Mass Incarceration. Mass Incarceration arose out of the cries for 'law and order' in the late 50's as the Civil Rights Movement gained strength and momentum. Even though the civil right demonstration were non-violent movements, yet they were characterized as acts of violence and terror by Whites. They saw the efforts by Blacks for freedom and equal rights as a 'breakdown in law and order.' Once the Civil Rights Act became the law of the land the public conversation moved from segregation to crime. The Jim Crow system of segregation was dismantled and gave birth to a new Jim Crow system of Mass Incarceration.

Meanwhile white American was passing stiffer laws and regulations like the Sentencing Reform Act of 1984. The Prison terms Reform Act of 1984 the US Government passed legislation requiring that our federal prison terms be restructured by the United States Sentencing Commission by 1987. Supposedly, the goal was to "explicitly linked sentencing to relevant conduct-offense characteristics-and sought to abolish unwarranted sentence disparity." Albonetti's presentation examined the following variables: guilty pleas, characteristics of defendants among drug offenders of three groups of defendants -black, brown and white who were sentenced in 1991 - 1992. Albonetti's findings showed prison terms disparity among non-whites; however, the U.S. Sentencing Commission said it was 'legally irrelevant' (1997). Another example of institutionalized racism at work again African Americans.

There is an abundance of criminological research supporting notions of blackcriminality that whites use to show there are biological and sociological reasons for imprisoning African Americans at a higher rate. Most of which, breed White fear and that leads to greater support for punitive or 'get tough' policies; thus, resulting in greater prison terms disparities (Wood 2020). In general, the number of African Americans increased significantly over the past several decades, while their population has declined. A small snapshot from 19801996shows the overall number of people incarcerated increased from 315,074 to1,138,984 (Lynch 2000). During that same time, the number of people in jails increased from 182,288 to 557,974 , which brings the total number of all incarcerated people to $1,696,958$, up from 497,362. It appears that as the incarceration numbers increase, so does the rate of African Americans being sentenced to correctional institutions at every level nationwide; and yet little, if anything is known about the viewpoints of this demographic.

The 'so-called' War on Drugs was a global campaign by the U.S. federal government proved to be very well received by Whites who were very resentful of the gains by Blacks following the Civil Rights era in housing, education, and economic prosperity. At the root of these disparities was racism .... Cultural narratives of Black criminality that were reinforced through crime statistics, early criminological scholarship, perpetuating ideologies of White supremacy and Black inferiority (Wood 2020). The War on Drugs continued through Democratic and Republican Presidential administrations for the last five decades; however, the harshest modern-day policies against Blacks and criminal justice system were doing the Clinton Administration. It was the Clinton Administration that 'endorsed the idea of a federal 'three strikes and you are out' law with his $\$ 30$ Billion Crime Bill which sent more African Americans males to prison than ever before in American history (Alexander, 95).

The third strategy for innovative strategies for adult leaders to address racism is by utilizing the theoretical framework of Critical Race Theory, which addresses the intersectionality of criminal law, justice, and race. Critical Race Theory (CRT) 'sprang up in the late 1980's when the Civil Rights Movement stalled; new theories were needed to cope with emerging forms of institutional or "colorblind" racism and a public that' seemed tired of hearing about race' (Delgado and Stefancic 2007). Their work provides the framework for this presentation because of their devotion to encouraging greater attention to crime and race as a guide for future dialogues and agendas.

\section{Critical Race Theory}

The issue of prison terms polices is critical to understanding the social disparity, racism and injustice towards African Americans and the U.S. criminal justice system as is understanding viewpoints from the population most impacted. The term Critical Race Theory is defined as a structure of power designed to benefit white people over all other races. Whites are considered to be society's elite and all other people are powerless. One of the key tenets of Critical Race Theory (CRT) suggests that 'racism is ordinary, not exceptional - the usual way that society does business-and thus represents the common, everyday experience of most people of color in this society' (Delgado and Stefancic 2007).

Further the statistics support revealed that incarceration has somehow drastically increased over the last 50 years. This is 
overly important when understanding systemic racism in the criminal justice system because the number of increased prison sentences have not been equally distributed in one social or geographic space. The over-saturation of incarceration in our society has, unfortunately, hit the African American communities harder than it did those of white skin color (Lynch 2000). This occurrence is a direct result of institutional racism. The second tenet of CRT suggests 'material determination' due to the fact that there is little to no incentive for white people to change from their position of 'white privilege'; because racism advances the self-interest of the White elites. It seems no matter what a person of color achieves there standing with the White elites remains the same. The third tenet of CRT is focused on the 'social construction of race and the idea of 'differential racialization' in way society or the dominant culture deals with diverse groups of minorities (Delgado and Stefancic 2007). The outcomes and effects of race discrimination and inequalities embedded within institutions themselves can predict how the injured sees self and copes within a society which racially biased and unfair.

African Americans have the highest rate of incarceration in the U.S. According to 'The Prison terms Project,' which submitted the United Nations in April 2018 revealed racial disparity against African Americans at every level of our criminal justice system, and especially in our prison terms polices (2018). The Sentencing Project was a special 'rapporteur on contemporary forms of racism, racial discrimination, xenophobia, and related intolerance.' More needs to be known about the prison terms policies in the United States and its application to African Americans and viewpoints of this important population.

Remarkably interesting research on mandatory prison terms and racial disparity in research by authors Starr and Rehavi (2013) conducted descriptive work to assess the role of prosecutors and the effect of Booker and found that race directly impacts pre-prison terms decision towards African Americans, especially males. Moreover, authors' research pointed to a need for 'presumptive sentence control.' This is useful to my work because it says to the need for more federal studies on prison terms. Studies reveal a direct relationship between racial disparity on prison terms between black and white defendants in capital cases. It was a descriptive presentation that used a national survey to see if defendants' race was the main factor in receiving the death penalty vs. life with no parole as the maximum sentence for their capital case. The findings were as follows: "respondents who were told life-without-parole was the maximum sentence were not significantly more likely to convict Black $(67.7 \%)$ than White $(66.7 \%)$ defendants. However, when death was the maximum sentence, respondents presented with Black defendants were significantly more likely to convict $(80.0 \%)$ than were those with White defendants (55.1\%)" (Glaser2015).

One of the most significant findings was prison terms data on offenders convicted of crack-cocaine and powder-cocaine offenses. Although decision-making of all criminal justice actors generally, and prosecutors specifically, has been the subject of much research, studies have yet to resolve the nature and outcome of their "autonomous" discretion. This autonomy becomes especially salient regarding prosecutorial decisions for substantial assistance departures. In deciding who receives a substantial assistance departure, the prosecutor has carte blanche power" (Hartley 2007).

\section{Conclusion}

There is a direct correlation between racism and unfair/unjust prison terms as the major systemic criminal justice problem impact the African American community. The criminalization of African Americans, especially males has been long standing American practices which is supported by crime statistics falsely showing that Blacks were committing more violent crimes and therefore needed harsher criminal prison terms.

Overall limitations of a body of research reveal lack of perceptions on prison terms on the age and populations most directly impacted by criminal prison terms decisions. Review of the literature revealed that most available research literature only looks at perceptions of prison terms by the criminal justice system using community-based samples.

Findings and recommendations from this paper can be useful in the following three areas: (1) to frame community discussions on the origins of institutional racism in America; (2) to provide greater understanding of systemic criminal justice problems in prison terms for African Americans; and (3) to enhance adult learners' opportunities in the provision of quality community service using an informed and evidence-based platform for discussion. One of the key tenets of Critical Race Theory (CRT) suggests that 'racism is ordinary, not exceptional- the usual way that society does business - and thus represents the common, everyday experience of most people of color. Still, more needs to be known about the lack of fairness on criminal justice systems in the United States and African Americans to ensure continued progress towards achieving the American dream and informing future discussions on critical community issues and concerns.

Lastly, in support of the aforementioned findings and recommendations from this paper the following suggested initiatives would be useful. (1) Find contemporary news articles and stories to help incorporate the issues of race/racism into your studies. Use this approach to help frame community discussions on the origins of institutional racism in America; (2) Research and find ways to embrace challenging viewpoints and look to provide greater understanding of systemic criminal justice problems in prison terms for African Americans; and (3) Define prejudice and bias and explore ways to enhance adult learners' opportunities in the provision of quality community service using an informed and evidence-based platform for discussion.

\section{References}

[1] Albonetti, C. (1997). Prison terms under the Federal Prison terms Guidelines: Effects of Defendant Characteristics, Guilty Pleas, and Departures on Sentence Outcomes for Drug Offenses, 1991-1992. 
Law \& Society Review, 31(4), 789-822. doi: $10.2307 / 3053987$.

[2] Alexander, M. (2020). The New Jim Crow: Mass Incarceration in the Age of Colorblindness. The New Press.

[3] Bartleby (2020). Essay -The Rebirth Of Caste By Michelle Alexander - 1744 Words | Bartleby p,1

[4] Blakeney, A.M. (2011. Antiracist pedagogy: Definition, theory, purpose, and professional development. Journal of Curriculum \&Pedogogy 2(1), 119-32.

[5] Black, D. (1976). The Behavior of Law. New York: Academic Press.

[6] Bjerk, D. (2005). Making the crime fit the penalty: The role of prosecutorial discretion under mandatory minimum prison terms Journal of Law and Economics, 48, 591-625.

[7] "Crime in the U.S.: Key questions answered | Pew Research ..." 20 Nov. 2020, https://www.pewresearch.org/fact-

$\operatorname{tank} / 2020 / 11 / 20 /$ facts-about-crime-in-the-u-s/.

"Convict leasing - Wikipedia." https://en.wikipedia.org/wiki/Convict_lease.

[8] Delgado, R \&Stefancic, J. (2007). Critical Race Theory and Criminal Justice, Humanity \& Society. Vol. 31 (May/August: 133-145).

[9] Du Buois, W.E.B. (1903). The Souls of black Folk. New York.

[10] Fischman, J., \& Schanzenbach, M. (2012). Racial disparities under the Federal Sentencing Guidelines: The role of judicial discretion and mandatory minimums. Journal of Empirical Legal Studies, 9(4), 729-764.

[11] Glaser, J., Martin, K. D., \& Kahn, K. B. (2015). Possibility of death sentence has divergent Effect on verdicts for Black and White defendants. Law and Human Behavior, 39(6), 539-546. https://doi.org/10.1037/lhb0000146

[12] Glaude, E. (2016) Democracy in Black: How race still enslaves the American soul. Random House LLC.

[13] Hartley, R., Maddan, S., \& Spohn, C. (2007). Prosecutorial discretion: An examination of substantial assistance departures in federal crackcocaine and powder cocaine cases. Justice Quarterly, 24, 382-407.

[14] Headley, A. and Wright, J. (2020). Is Representation Enough? Racial Disparities in Levels of Force and Arrests by Police. Public Administration Review, November/December 2020, Vol. 80, No.6, Wiley Blackwell.

[15] Johnson, H., Travis Wolfe, N., Jones, M. (2011). History of Criminal Justice. New York: Routledge.

[16] Kennedy, Stetson (2011). Jim Crow Guide to the U. S. A.: The Laws, Customs and Etiquette Governing the Conduct of Nonwhites and Other Minorities As Second-Class Citizens, University of Alabama Press.

[17] Langley, B.M. (2014). The Black Experience in the United States: An Examination of Lynching and Segregation as Instruments of Genocide, University of South Florida, think.harder89@gmail.com.

[18] "Report to the United Nations on Racial Disparities in the U.S. Criminal Justice System " (April 19, 2018). https://www.sentencingproject.org/publications/unreport-on-racial-disparities/.

[19] Roberts, Dorothy E., "The Social and Moral Cost of Mass Incarceration in African American Communities" (2004). Faculty Scholarship at Penn Law. 583. https://scholarship.law.upenn.edu/faculty_scholarship/ 5Slavery in the United States - Wikipedia

[20] Van Cleve, N., \& Mayes, L. (2018). Criminal Justice Through "Colorblind" Lenses: A Call to Examine the Mutual Constitution of Race and Criminal Justice. Law \& Social Inquiry, 40(2), 406-432.

[21] Wood, Peter (2003). "The Birth of Race-Based Slavery". Slate. (May 19, 2015): Reprinted from "Strange New Land: Africans in Colonial America" by Peter H. Wood with permission from Oxford University Press. (C)1996, 2003. 